\title{
Pengaruh Harga, Review Produk, Jaminan Keamanan Terhadap Keputusan Pembelian Produk Pada Situs Jual Beli Online Shopee
}

\author{
Jenni Veronika Br Ginting*, Chairia, Polin Ramles \\ Prodi D-3 Akuntansi, ITB Indonesia, Sumatera Utara, Indonesia \\ Email: 1,*veronikarossy11@gmail.com, ${ }^{2}$ chairialubis20@gmail.com, ${ }^{3}$ stevanohutabarat@gmail.com \\ Email Penulis Korespondensi: veronikarossy11@gmail.com \\ Submitted: 21/11/2021; Accepted: 28/11/2021; Published: 30/11/2021
}

\begin{abstract}
Abstrak-Pasar modern tidak lagi dijalankan dengan cara transaksi secara tatap muka, pasar modern saat ini sudah menggunakan sistem online dimana dengan menggunakan sebuah sistem berbasis aplikasi mobile maupun desktop sudah dapat mengaplikasikan sistem dalam hal jual beli hal tersebut biasa disebut dengan e-commerce, salah satu e-commerce yang sangat popular di kalangan masyarakat Indonesia yaitu shopee dikarenakan pengguna shopee sangat banyak, para pebisnis usaha sangat banyak memulai berdagang di aplikas shopee, proses persaingan dagang yang semakin hari semakin ketat harus membangun dan melihat peluang apa saja yang dapat meningkatkan kegiatan bisnis dan pencapaian terhadap target bisnis. Pentingnya diketahui beberapa pengaruh keputusan pembeli terhadap pembelajaan online di shopee untuk mengetahui target dan sasaran yang baik dalam meningkatkan kualitas maupun kuantitas jual beli online. Pada penelitian ini ingin diketahui pengaruh harga, riview produk dan jaminan keamanan sebagai variabel bebas terhadap keputusan pembelian produk. Ditemukan hasil dari harga, review produk dan keamanan pembelian memiliki peranan penting dan berpengaruh positif terhadap keputusan pembelian produk di shopee.
\end{abstract}

Kata Kunci: Harga; Review Produk; Keamanan; Keputusan Pembelian

Abstract-Modern markets are no longer run by way of face-to-face transactions, modern markets are now using an online system where by using a mobile or desktop application-based system, you can apply the system in terms of buying and selling, this is commonly called e-commerce, one of which is e-commerce. one e-commerce that is very popular among the people of Indonesia, namely shopee because there are so many shopee users, a lot of business people start trading on the shope application, the process of trade competition is getting tougher day by day they have to build and see what opportunities can increase business activities and achievement of business targets. It is important to know the influence of buyers' decisions on online shopping at shope to find out good targets and targets in increasing the quality and quantity of buying and selling online. In this study, we want to know the effect of price, product reviews and security guarantees as independent variables on product purchasing decisions. It was found that prices, product reviews and purchase safety have an important role and have a positive effect on product purchasing decisions at shopee.

Keywords: Price; Product Review; Security; Purchase Decision

\section{PENDAHULUAN}

Bisnis merupakan salah satu yang tidak terlepas dari kehidupan manusia, hampir diseluruh bidang yang menghasilkan benefit disebut dengan bisnis. Bisnis juga disebut sebagai kegiatan baik indvidu maupun dilakukan perkelompok hingga membentuk sebuah perusahaan besar memberikan sebuah tawaran produk maupun jasa sebagai hal yang akan disuguhkan untuk mencapai benefit dalam bentuk uang maupun keuntungan yang dapat memenuhi kebutuhan masyarakat itu sendiri, pada umumnya kebutuhan yang ingin dihasilkan paling banyak merupakan uang baik cash maupun non cash. Bisnis telah menjadi alternatif utama pada masa perkembangan teknologi yang semakin marak sebagai cara lain untuk dapat memenuhi kebutuhan kehidupan manusia(WIDIANINGRUM; Enggar., 2020).

Era teknologi pada masa saat ini merupakan teknologi yang membuat manusia sulit terlepas olehnya karena setiap kegiatan dilakukan dalam satu genggaman saja, kegiatan yang didominasi oleh teknologi saat ini merupakan kegiatan bisnis(Juanita, 2017). Bisnis sudah tidak hanya dapat dilakukan dengan cara memiliki tempat usaha disuatu wilayah dan melakukan proses transaksi secara tradisional dimana pembeli mendatangi tempat usaha dan membeli barang dan mendapatkan uang cash, proses transaksi saat ini dilakukan dengan bantuan teknologi dimana pembeli dan penjual memiliki sebuah aplikasi sebagai perantara dimana proses pembelian dilakukan dengan hanphone yang memiliki kuota internet, pembelian tidak hanya dalam satu wilayah saja tetapi juga menjangkau pasar seluruh pasar di Indonesia hingga pasar internasional yang telah bekerja sama dengan aplikasi tersebut (Fauzi et al., 2018).

Aplikasi yang membantu proses jual beli secara online disebut dengan e-commerce, sudah sangat banyak jenis platform yang menyediakan jasa terhadap transaksi jual beli online. Adapun jenis e-commerce seperti lazada, Blibli.com, toko pedia, shopee dan lain-lain. Adanya aplikasi ini sangat membantu banyak masyarakat dalam membantu memulai usaha dan bisnisnya untuk memenuhi kebutuhan kehidupan baik individual maupun perkelompok (Manis et al., 2021). Aplikasi yang paling banyak digunakan oleh masyarakat Indonesia saat ini merupakan e-commerce dari Shopee ada sebanyak 72,4 penggunaan dalam bentuk mobile dan 2,13\% dalam bentuk desktop dimana pengunjung situs tersebut sebanyak 120 juta jiwa yang mengaksesnya dan mengunjungi shopee dalam kurun waktu satu bulan, baik itu pembeli maupun penjual. Banyaknya jumlah masyarakat pengguna dan pemulai bisnis membuat persaingan semakin meningkat.

Dalam melakukan kegiatan bisnis tentu tidak terlepas dari sebuah strategi agar mengetahui setiap langkah dan upaya yang perlu dilakukan untuk tetap dapat bertahan dalam sebuah kegiatan e-commerce. Pentingnya mengetahui strategi dalam sebuah bisnis sama seperti mengasah ujung tombak untuk dapat bertahan pada pesangian bisnis, untuk 
jenis produk yang ditawarkan bisa berbagai jenis dan orang yang menawarkan produk yang sama juga sangat banyak sehingga untuk mempertahankan dan mendapatkan keputusan konsumen dalam membeli produk yang ditawarkan.

Dalam mendapatkan keputusan dan kepercayaan konsumen dalam membeli produk tentunya terhadap beberapa hal yang wajib diketahui dan perlu dicari tahu, hal-hal apa saja yang menjadi bahan pertimbangan dalam keputusan pembeli untuk membeli sebuah produk, setiap konsumen tentu memiliki perbedaan pendapat terhadap pengambilan keputusan pembelian terhadap suatu produk terutama produk yang dipasarkan secara online di shopee. Dari beberapa penelitian memperlihatkan beberapa variabel yang menjadi pertimbangan terhadap pembelian sebuah produk baik secara berkala dan adapun beberapa faktor pengaruh dari "harga" Karena banyak masayarakat yang memposisikan kualitas produk terhadap harga yang sesuai dengan keadaan masing-masing keuangan pembeli .

Faktor lainnya menyatakan bahwa hal yang membuat pembeli tertarik untuk mengambil keputusan beli pada layanan jual beli online Karena melihat penjual menunjukan kualitas produk yang lebih sering disebut dengan "review produk" hal tersebut dilakukan bisa menggunakan fasilitas online lainnya tetapi shopee telah menambahkan fitur untuk meletakan review produk dengan tepat dan aplikasi lain sebagai penyebar luas review produk. Faktor lain yang juga sangat penting dalam melakukan jual beli online di shopee adalah keamanan, banyak pembeli memutuskan membeli jika sudah merasa aman terhadap produk yang dibeli, hal tersebut dapat diperoleh dari, komentar oleh para pembeli sebelumnya.

Banyak peneliti terdahulu yang menyatakan bahwa pengaruh harga mempengaruhi sebesar 43,2 persen dari keseluruhan variabel dalam pembelian pada swalayan peterongan semarang dan citra merek mendominasi sebsar 70 persen terhadap keputusan pembelian (AMILIA, 2017). Penelitian terdahulu berhubungan dengan merek memiliki nilai positif sebesar $82 \%$ terhadap perilaku konsumen yang memberikan keputusan pembelian terhadap produk Zara (Saputri, 2016). Penelitian terdahulu terhadap harga sangat beraneka pilihan dimana nilai pengaruh terhadap harga dianggap sangat berpengaruh positif signifikansi terhadap keputusan konsumen dalam membeli sebuah produk (Faroh, 2017).

Penelitian terhadulu terhadap perilaku konsumen dalam menentukan keputusan pembelian dimana variabel merupakan strategi dalam review produk yang dipasarkan melalui media sosial mendapatkan nilai berpengaruh signifikansi postif terhadap pembelian produk di tokopedia salah satu situs jual beli e-commerce (Sianipar \& Yoestini, 2021). Dan penelitian lainnya menyatakan review produk terhadap memperoleh hasil yang sangat positif secara signifikansi terhadap keputusan pembelian secara online pada marketplace (Saputra, 2021).

Penelitian terdahulu yang telah dilakukan dalam melihat keputusan terhadap pembelian dalam aplikasi atau situs online mendapatkan penerimaan secara silmultan dan penolakan yang signifikan negatif pada situs tokopedia (Husniadi, 2021). Pada penelitian ini akan melihat dari tiga variabel harga terhadap keputusan pembelian, variabel review produk terhadap keputusan pembelian, dan keamanan terhadap keputusan pembelian secara online pada Shopee sebagai ecommerce yang dituju.

\section{METODE PENELITIAN}

\subsection{Pengumpulan data}

Pengumpulan data dilakukan untuk mendapatkan data yang nyata dan membuat kualitas dari penelitian benar adanya, adapun tahapan yang dilakukan penelitian dalam pengumpulan data adalah sebagai berikut ini (Muspah et al., 2021):

1. Survey

Dilakukan teknik survey yang merupakan tahapan menanyakan langsung terhadap banyak penggunaan e-commerce yang digunakan sehingga diketahui secara lagsung juga permasalahan yang terjadi, hal tersebut dilakukan untuk mengetahui tahapan dan proses yang akan dilakukan dalam menyelesaikan sebuah permasalahan.

2. Kuesioner

Kueioner merupakan data pertanyaaan yang dibagikan kepada beberapa respondensi yang terkait terhadap permasalahan yang dihadapi untuk mengetahui hal apa saja yang menjadi kendala, harapan, pengaruh dan yang sering terjadi dalam sebuah fenomena tertentu. Butir pertanyaan dan jawaban responden akan membantu peneliti dalam menemukan fakta baru yang terjadi pada setiap permasalahan.

3. Dokumentasi

Dokumentasi digunakan agar peneliti dapat mengumpulkan penelitian yang telah dilakukan untuk menjadi sebuah laporan dan bukti tertulis maupun tidak tertulis dalam memenuhi kebutuhan sebuah penelitian.

4. Studi Pustaka

Studi pustaka digunakan untuk mempermudah peneliti dalam mendapatkan referensi dari penelitian-penelitian sebelumnya untuk mempermudah peneliti dalam meningkatkan kulitas penelitian dan membuat penelitian lebih terarah.

\subsection{Analisis Kuantitatif}

Pengujian ini menggunakan analiss kuantitatif untuk mengetahui hasil berupa perhitungan, data statistic, matetatika dimana data hasil merupakan perolehan dari data kuesioner, adapun hal-hal yang dilakukan sebagai berikut ini(Karina et al., 2020):

1. Asumsi Klasik

a. Uji Normalitas 
Data yang dapat dikatakan normal jika nilai signifikaninya yang dimiliki pada komlogrov sebanyak >0,05 jika kurang "tidak normal" dapat dilakukan dengan hisogram dimana grafik naik turun membentuk puncak gunung, pplot, komlogrov.

b. Uji Multikolenaritas engan melihat nilai VIF (varience inflation factor) dibawah 10, dan tolerance value harus diatas $>0,1$

c. Uji Heterokedatisitas

Uji ini dapat dilihat pada scatterplot dimana harus menyebar titiknya dan pola tidak boleh bertumpuk.

2. Regresi Linear Berganda

Pada regresi berganda ini akan menampilkan hasil data dari uji SPSS dalam membaca hasil hipotesis dan relasi antara variabel independen dan variabel dependen.

\subsection{Harga Produk}

Harga produk merupkan sebuah nilai yang ditetapkan terhadap sebuah benda yang memiliki manfaat dan memiliki nilai jual untuk memenuhi kebutuhan bersama, adanya harga produk yang ditawarkan memperlihatkan terhadap adanya kualitas dan kuantitas sebuah produk. Harga sebuah produk terkadang menjadi sebuah permasalahan dalam sebuah produk tetapi sebagian customer tidak menganggap harga menjadi masalah dalam sebuah produk. Karena nilai sebuah produk memang terlhat dari sebuah harga (Saputra, 2021).

\subsection{Review Produk}

Review produk merupakan tampilan yang memperlihatkan kualitas dan aspek-aspek yang ada pada sebuah produk sebagai pertunjukan yang menampilkan kelebihan dan kekurangan sebuah produk, review produk sudah lama diterapkan dalam jual beli online, bertujuan agar pembeli tahu terhadap apa yang akan didapatkan oleh pembeli sebuah produk dan dalam review produk ini biasanya menggunakan bantuan dari promosi media sosial untuk membantu memperluas jaringan pasar nasional hingga ke manca negara, review produk dapat disebut juga teknik pemasaran seperti iklan yang ditayangkan di layar televisi (Silalahi, 2020). Dalam review produk dapat dilakukan beberapa hal seperti memberitahu kelebihan atau keunggulan dalam pembelian, menunjukan kekurangan seminimal mungkin, dari review produk terdapat pesan dan cerminan dari sebuah produk dan asumsi konsumen dan meningkatkan pengetahuan konsumen terhadap jenis barang maupun jasa yang dipasarkan secara terbuka, pentingnya mengetahui apa hal yang akan didapatkan membuat konsumen dapat memilih kepada apa menempatkan pilihan (Sianipar \& Yoestini, 2021).

\subsection{Keamanan}

Dalam setiap aspek tentunya seseorang mengharapkan jaminan terhadap dirinya, sama halnya dengan jaminan dalam membeli sebuah barang dalam keadaan online. Jual beli barang e-commerce memang sangat disenangi oleh banyak kalangan saat ini, tetapi menjadi celah bagi para penipu yang tidak bertanggung jawab dalam mencari korban, sehingga membuat banyak orang yang harus berhati-hati mnentukan dan memilik sebuah produk yang akan digunakan. Keamanan merupakan perolehan kepercayaan terhadap sabuah produk dan brand tertentu sehingga perlu dalam meningkatkan keamanan dan mengetahui tingkat keamanan dalam membeli sebuah produk untuk menghindari beberapa hal yang tidak di inginkan dikemudian hari (Husniadi, 2021).

\subsection{Keputusan Pembelian}

Keputusan pembelian merupakan pendapat dan keinginan yang didorong berdasarkan beberapa pengetahuan dan informasi yang dimilki dalam mempertimbangkan diri dalam membeli sebuah produk baik barang maupun jasa. Adanya keputusan pembelian terhadap sebuah produk membuat meningkatnya benefit bagi penjual produk yang dituju. Keputusan pembelian merupakan target utama yang ingin dicapai oleh berbagai kalangan penjual dalam menjajarkan pasarannya. Berbagai kegiatan strategi dilakukan untuk mendapatkan minat dan keputusan pembeli terhadap produk yang ditawarkan(Faroh, 2017).

\subsection{Shopee}

Shopee adalah sebuah situs e-commerce yang sangat terkenal di Indonesia, Malaysia, china, dan negara asia yang menjalin kerja sama dengannya, shopee memiliki banyak keunggulan baik dalam memberikan kemudahan dalam proses belanja, keamanan dan banyak hal lainnya. Shopee merupakan perusahaan yang memiliki pusat di Singapore. Shopee menawarkan orang-orang untuk membuka peluang berbisnis baik dalam membuka bisnis berupa barang, makanan, minuman dan jasa, yang memiliki perantara pengantaran dalam mempermudah dan memperluas jangkauan.

\section{HASIL DAN PEMBAHASAN}

Penelitian memperlihatkan hasil dari masing-masing pengaruh terhadap variabel bebas yaitu harga, review produk, keamanan dalam pembelian terhadap keputusan pembelian, dimana hasil dari jawaban 42 responden diolah menggunakan tools statistic SPSS sehingga hasil yang didapatkan sebagai berikut ini: 


\subsection{UJi Asumsi Klasik}

\section{Uji Normalitas}

Data yang dapat dikatakan normal jika nilai signifikansinya yang dimiliki pada komlogrov sebanyak $>0,05$ sehingga dapat dikatakan data normal karena data Asymp. Sig sebanyak 0,108 > 0,05 terlihat pada tabel di bawah ini:

Tabel 1. One-Sample Kolmogorov-Smirnov Test

\begin{tabular}{llr}
\hline & & $\begin{array}{c}\text { Unstandardized } \\
\text { Residual }\end{array}$ \\
$\mathrm{N}$ & & 42 \\
\hline Normal Parameters ${ }^{\mathrm{a}, \mathrm{b}}$ & Mean & .0000000 \\
& Std. Deviation & 1.20498045 \\
Most Extreme Differences & Absolute & .124 \\
& Positive & .078 \\
Test Statistic & Negative & -.124 \\
Asymp. Sig. (2-tailed) & & .124 \\
\hline
\end{tabular}
a. Test distribution is Normal.
b. Calculated from data.
c. Lilliefors Significance Correction.

2 Uji Multikolinearitas

Dengan melihat nilai VIF (varience inflation factor) dibawah 10, dan tolerance value harus diatas $>0,1$ dan hasil dinyatakan tidak terkena multikolinearitas karena tampak hasil pada VIF baik pada variabel Harga sebesar 1,058 < 10.00, variabel Review Produk memiliki nilai VIF sebesar

Tabel 2. Coefficients ${ }^{\mathrm{a}}$

\begin{tabular}{|c|c|c|c|c|c|c|c|c|}
\hline \multirow{2}{*}{\multicolumn{2}{|c|}{ Model }} & \multicolumn{2}{|c|}{$\begin{array}{l}\text { Unstandardized } \\
\text { Coefficients }\end{array}$} & \multicolumn{2}{|l|}{$\begin{array}{l}\text { Standardized } \\
\text { Coefficients }\end{array}$} & \multirow[b]{2}{*}{ Sig. } & \multicolumn{2}{|c|}{ Collinearity Statistics } \\
\hline & & B & Std. Error & Beta & $\mathrm{t}$ & & Tolerance & VIF \\
\hline 1 & (Constant) & 7.841 & 6.150 & & 1.275 & .210 & & \\
\hline & Harga & .325 & .168 & .300 & 1.935 & .060 & .946 & 1.058 \\
\hline & Review Produk & .028 & .214 & .020 & .133 & .895 & .962 & 1.039 \\
\hline & Keamanan & .199 & .161 & .188 & 1.235 & .224 & .982 & 1.019 \\
\hline
\end{tabular}

a. Dependent Variable: Keputusan Pembelian

3 Uji Heterokedatisitas

Uji ini dapat dilihat pada scatterplot dimana harus menyebar titiknya dan pola tidak boleh bertumpuk. Sehingga data juga tidak teridentifikasi terkena Heterokedatisitas dapat terlihat pada gambar berikut ini:

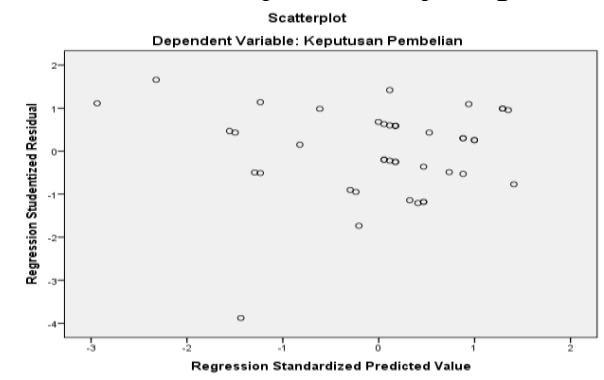

Gambar 1. Uji Heterokedatisitas

\subsection{Hasil Pengujian}

Hasil yang ditemukan dari tabel 4 terlihat

Tabel 4. Hasil Regresi

\begin{tabular}{llrrrr}
\hline & \multirow{2}{*}{ Model } & \multicolumn{2}{c}{ Uji T } & \multicolumn{2}{c}{ Uji F } \\
& \multicolumn{1}{c}{$\mathrm{t}^{2}$} & Sig. & \multicolumn{1}{c}{$\mathrm{t}$} & Sig. \\
\hline 1 & (Constant) & 1.275 & .210 & & \\
& Harga & 1.935 & .060 & 3.753 & $.004^{\mathrm{b}}$ \\
& Review Produk & .133 & .895 & & \\
Keamanan & 1.235 & .224 & & \\
\hline
\end{tabular}

a. Dependent Variable: Keputusan Pembelian

Hasil yang diperoleh dalam pengujn model regresi ini dalam melihat masing-masing hubungan antara variabel harga yang menjadi variabel X1, variabel X2 yaitu Review Produk dan keamanan pembelian menjadi X3 terhadap 
keputusan pembelian yang dilakukan oleh konsumen merupakan variabel (Y). Adapun hasil yang diperoleh dari data yang telah diuji pada aplikasi SPSS mendapatkan persamaan berupa: $\mathrm{Y}=0,060 \mathrm{X} 1+0,895 \mathrm{X} 2+$ 0,224 X3 berdasarkan hasil dari persamaan sehingga membentuk presepsi sebagai berikut ini:

1. Keseluruhan variabel bebas yaitu variabel harga yang menjadi variabel X1, variabel X2 yaitu Review Produk dan keamanan pembelian menjadi X3 memiliki arah hasil yang positif terhadap target $\mathrm{Y}$ yang merupakan variabel keputusan pembelian.

2. Pada koefisien variabel harga memiliki nilai 0,60 menyatakan sebesar $6 \%$ pengaruh dari harga terhadap variabel keputusan pembeli, berarti dari $100 \%$ responden tidak mempermasalahkan harga terhadap keputusan pembelian, lebih tertarik kepada variabel pendukung variabel harga terhadap keputusan pembelian lainnya sebagai pengaruh terhadap hasil dari keputusan pembelian. Hasil pada pengujian memperlihatkan pengaruh bernilai signifikansi positif. Pada nilai $\mathrm{H}_{\mathrm{a}}$ diterima dan $\mathrm{H}_{0}$ ditolak.

3. Koefisien variabel review produk mendapatkan nilai sebesar 0,895 dimana sebesar $86 \%$ responden mendapatkan hasil bahwa variabel X2 mendapatkan nilai yang sangat berpengaruh besar terhadap keputusan pembelian. Hasil pada pengujian memperlihatkan pengaruh variabel review produk terhadap keputusan pembelian bernilai signifikansi positif. Pada nilai $\mathrm{H}_{\mathrm{a}}$ diterima dan $\mathrm{H}_{0}$ diterima.

4. Koefisien keamanan mendapatkan nilai 0,224 dimana sebesar $22 \%$ responden mendapatkan hasil bahwa variabel X3 yaitu keamanan mendapatkan nilai yang sangat berpengaruh besar terhadap keputusan pembelian. Hasil pada pengujian memperlihatkan pengaruh variabel review produk terhadap keputusan pembelian bernilai signifikansi positif. Pada nilai $\mathrm{H}_{\mathrm{a}}$ diterima dan $\mathrm{H}_{0}$ diterima.

\section{KESIMPULAN}

Hasil dari keseluruhan pengujian mendapatkan bahwa variabel harga memiliki nilai berpengaruh signifikansi positif, review produk memiliki hasil berpengaruh signifikansi positif dan juga sama berpengaruh signifikansi positif juga terhadap hasil keputusan pembelian sebuah produk, penggunaan SPSS dalam melihat hasil respondensi mempermudah penelitian dalam memperoleh hasil dengan tepat dan cepat. Secara keseluruhan tingkat pengaruh masing-masing variabel bebas terhadap variabel terikat atau target variabel yaitu keputusan pembelian berpengaruh dengan nilai tertinggi sebesar $86 \%$ dimana sisanya merupakan pengaruh dari variabel lainnya.

\section{REFERENCES}

AMILIA, S. (2017). Pengaruh Citra Merek, Harga, dan Kualitas Produk terhadap Keputusan Pembelian Handphone Merek Xiaomi di Kota Langsa. Jurnal Manajemen Dan Keuangan Unsam, 6(1), 660-669.

Faroh, W. N. (2017). Analisa Pengaruh Harga, Promosi, dan Pelayanan Terhadap Keputusan Pembelian. Journal Ilmiah Prodi Manajemen, 4(2), 3-24. Harga, Promosi, Pelayanan, Keputusan Pembelian

Fauzi, R., Wibowo, S., \& Putri, D. Y. (2018). Fauzi, R., Wibowo, S., \& Putri, D. Y. (2018). Perancangan Aplikasi Marketplace Jasa Percetakan Berbasis Website. Fountain of Informatics Journal, 3(1), 5. https://doi.org/10.21111/fij.v3i1.1824Perancangan Aplikasi Marketplace Jasa Percetakan Berbasis Webs. Fountain of Informatics Journal, $3(1)$, 5. https://doi.org/10.21111/fij.v3i1.1824

Husniadi. (2021). Analisis Kepercayaan Konsumen, Kualitas Pelayanan Dan Keamanan Produk Terhadap Keputusan Pembelian Pada Toko Online Wulan Kokula Selama Masa COVID -19. Jurnal Kebangsaan, 10(20), 52-58. http://www.jurnal.uniki.ac.id/index.php/jkb/article/view/92

Juanita, S. (2017). Analisa Strategi Bisnis Penjualan Online. Konferensi Nasional ICT-M Politeknik Telkom, 254-260. http://journals.telkomuniversity.ac.id/knip/article/view/557

Karina, V., Gadzali, S. S., \& Budiarti, I. (2020). Pengaruh Lingkungan Kerja Terhadap Kinerja Karyawan Pada Pt. Hade Dinamis Sejahtera. The World of Business Administration Journal, September, 117-123. https://doi.org/10.37950/wbaj.v2i1.916

Manis, P. L., Batubara, K., Siagian, Y., Syah, A. Z., Amin, M., \& Kifti, W. M. (2021). Pelatihan Penggunaan E-Commerce Sebagai Upaya Pemasaran Penjualan Produk Kerajinan Rumah Tangga Ibu-ibu PKK Desa. 2(1), 25-30.

Muspah, E. Y., Gani, A., \& Ramlawati. (2021). Pengaruh Hard Skill dan Soft Skill Terhadap Kinerja Pegawai pada Kantor Camat Galesong Utara di Kabupaten Takalar. Ilmu Ekonomi, 4(1), 131-142.

Saputra, A. D. (2021). ... Produk, Harga Dan Online Customer Review And Rating Terhadap Keputusan Pembelian Di Tokopedia (Studi Kasus di Universitas Muhammadiyah http://eprints.ums.ac.id/id/eprint/93489\%0Ahttp://eprints.ums.ac.id/93489/10/NASKAH PUBLIKASI.pdf

Saputri, M. E. (2016). Pengaruh Perilaku Konsumen Terhadap Pembelian Online Produk Fashion Pada Zalora Indonesia the Effect of Consumer Behavior Toward the Online Purchase of Fashion Product of Zalora Indonesia. Sosioteknologi, 15(2), $291-297$.

Sianipar, F. A. H., \& Yoestini. (2021). ANALISIS PENGARUH CUSTOMER REVIEW DAN CUSTOMER RATING TERHADAP KEPUTUSAN PEMBELIAN PRODUK DI ONLINE MARKETPLACE (Studi Pada Mahasiswa Pengguna Tokopedia di Kota Semarang) Frederick Alvi Herzegovino Sianipar, Dr. E. Dra. Hj. Yoestini, M.Si 1. Diponegoro Journal of Management, $10(2000), 1-10$.

Silalahi, N. (2020). TIN: Terapan Informatika Nusantara Penentuan Strategi Promosi Universitas Budi Darma Menggunakan Algoritma K-Means Clustering TIN : Terapan Informatika Nusantara. 1(1), 40-46.

WIDIANINGRUM; Enggar. (2020). PENGARUH EFIKASI DIRI DAN LINGKUNGAN KELUARGA TERHADAP MINAT WIRAUSAHA SISWA SMK DI MASA PANDEMI COVID-19. POINT. Ekonomi Bisnis. http://ejournals.umma.ac.id/index.php/point/article/view/726 